Article

\title{
Rocio Virus Encephalitis: In Silico Evidence for Drug Repurposing
}

\author{
João Pedro Sagini ${ }^{1}$, Pablo Ricardo Arantes ${ }^{2}$, Conrado Pedebos ${ }^{3}$ and Rodrigo Ligabue-Braun ${ }^{1,4}, * \mathbb{C}$ \\ 1 Graduate Program in Biological Sciences (PPGBio), Federal University of Health Sciences of Porto \\ Alegre (UFCSPA), Sarmento Leite, 245, Porto Alegre 90050-170, Brazil; pedrosagini@gmail.com \\ 2 Department of Bioengineering, University of California, Riverside, CA 92521, USA; pabloa@ucr.edu \\ 3 Department of Biochemistry, University of Oxford, Oxford OX1 3QU, UK; conrado.pedebos@bioch.ox.ac.uk \\ 4 Department of Pharmacosciences, Federal University of Health Sciences of Porto Alegre (UFCSPA), \\ Sarmento Leite, 245, Porto Alegre 90050-170, Brazil \\ * Correspondence: rodrigolb@ufcspa.edu.br; Tel.: +55-51-3303-8759
}

check for updates

Citation: Sagini, J.P.; Arantes, P.R.; Pedebos, C.; Ligabue-Braun, R. Rocio Virus Encephalitis: In Silico Evidence for Drug Repurposing. Macromol 2022, 2, 100-112. https://doi.org/ $10.3390 /$ macromol2010006

Academic Editor: Ana María Díez-Pascual

Received: 14 December 2021

Accepted: 5 February 2022

Published: 13 February 2022

Publisher's Note: MDPI stays neutral with regard to jurisdictional claims in published maps and institutional affiliations.

Copyright: (c) 2022 by the authors. Licensee MDPI, Basel, Switzerland. This article is an open access article distributed under the terms and conditions of the Creative Commons Attribution (CC BY) license (https:/ / creativecommons.org/licenses/by/ $4.0 /)$.

\begin{abstract}
Arboviral diseases have a high incidence in Brazil and constitute a serious public health problem. Rocio virus (ROCV) is an arbovirus belonging to the family Flaviviridae. It was responsible for the emergence of an outbreak of encephalitis on the São Paulo state coast in the late 1970s. Although no recent case of this virus has been reported, data suggest the circulation of ROCV throughout the Brazilian territory. Given these indications and the strong presence of fundamental factors for the resurgence of emerging diseases in Brazil, we conducted this study using virtual screenings to identify targets and therapeutic molecules that could be redirected to fight infections related to ROCV. Herein, we demonstrated that the National List of Essential Medicines of the Brazilian Unified Health System (SUS) has several molecules that could be redirected to combat this flavivirus, namely simeprevir, daclatasvir, iloprost, and itraconazole. Among them, itraconazole was found to be an interesting candidate since it interacts with both structural and nonstructural proteins of this virus and it is a strong binder to the NS1 protein, as confirmed by molecular simulations.
\end{abstract}

Keywords: drug repurposing; emergent infection; molecular docking; rocio virus; NS1

\section{Introduction}

Arboviruses (arthropod-borne viruses) have become a global public health threat due to disordered urbanization, deforestation, garbage accumulation, and environmental changes [1]. Although dengue virus (DENV) is the most relevant arbovirus in Brazil, followed by yellow fever (YFV), zika (ZIKV), and chikungunya viruses (CHIKV), other pathogens have an emerging and re-emerging epidemic potential, such as Ilheus virus (ILHV), Oropouche virus (OROV), and Rocio virus (ROCV) [2].

ROCV is a flavivirus that was known to be responsible for the appearance of an outbreak of encephalitis on the coast of Brazil in the mid-1970s. It was recognized as the only encephalitis-causing flavivirus in South America in the 1970s and the second most important arbovirus at the time, second only to wild yellow fever. Its name was based on Iguape county's district in which it was first discovered in the Ribeira Valley, São Paulo [3,4]. Some authors have suggested that the outbreaks occurred during the period from 1973 to 1980, with approximately one thousand cases of the disease causing about one hundred deaths and two hundred patients with sequelae of the disease [4-8]. Symptoms of this arbovirus include nonspecific signs, such as bloating, headache, fever, respiratory complications, malaise, vomiting, lethargy, oropharyngeal and conjunctiva hyperemia, and neurological symptoms related to encephalitis, such as blindness, confusion, seizures, deafness, dysarthria, meningitis, and motor and reflex abnormalities. About $20 \%$ of those affected by the disease developed sequelae, such as senses dysfunctions, dysphagia, dysarthria, memory, motor, and balance disorders, and paresthesia [5,9]. 
The molecular characterization of the ROCV indicates that its genome is $\sim 10.8 \mathrm{~Kb}$ in size, with an ORF comprising 10,275 nucleotides. This region encodes a 3425 amino acid polyprotein, which, after editing and cleavage processes, gives rise to ten common flavivirus proteins. These proteins are divided into two groups: structural proteins (premembrane, envelope, and capsid, also known as prM, E, and C) and nonstructural proteins (NS1, NS2A, NS2B, NS3, NS4A, NS4B, and NS5). Regarding the ORF of other flaviviruses, ROCV has a greater identity with ILHV (77.5\%) and, to a lesser extent, with other members of the Japanese encephalitis virus group (SLEV, WNV, MVEV, and JEV) [10].

Vector studies suggest that the virus is transmitted by blood-sucking mosquitoes of the species Psorophora ferox and Aedes scapularis. Additionally, some authors speculate about the susceptibility of mosquitoes of the genus Culex to this virus. These arthropods are known to inhabit the outbreak region and other regions in Brazil, such as the states of Goiás and Rio Grande do Sul, making these states susceptible to new cases. There is no evidence to suggest that interpersonal transmission occurs, since approximately $75 \%$ of patients affected by encephalitis lived in different households. This is an important finding, suggesting that the virus may be unable to sustain long epidemic cycles $[4,11,12]$. Although this epidemic has been limited to the Vale do Ribeira region, studies suggest the circulation of the virus throughout the country. Saivish et al. [13] detected viral ROCV RNA in 2 of 121 patients with a negative dengue diagnosis from a fever outbreak between 2011 and 2013. Therefore, it is estimated that many of the cases are under-reported given their similarity with other arboviruses, reinforcing the need to search for accurate diagnoses [14-16].

At this time, there is no specific antiviral treatment for arboviruses, and a rapid diagnosis is recommended to monitor the patient's clinical condition. Symptomatic treatment is indicated, with high consumption of fluids and a reduction in febrile symptoms by antipyretics. However, self-medication could cover the evolution of the disease. Hemorrhagic conditions, encephalopathies, and other complications must be assisted using specific procedures [17].

While considering potentially (re)emerging infectious diseases, it is essential to search for treatment alternatives that may aid quickly and effectively and do not have significant public health costs. Thus, the repurposing of drugs can be an attractive strategy, as it allows the reuse of drugs already approved by institutions for testing in silico, in vitro, and in vivo models and in clinical studies for different targets than those for which they were designed. This repositioning is a relevant factor since two-thirds of the drugs under investigation do not pass approval by clinical studies, either due to toxicity or lack of effectiveness [18-20].

Bearing in mind the strong presence of fundamental factors for the emergence and re-emergence of infections related to arboviruses in Brazil and the need to implement prevention, treatment, and control practices for those pathogens, we investigated the repurposing of drugs to fight infections related to ROCV. Our findings were based on the computational elucidation of ROCV proteins and their simulated interaction.

\section{Materials and Methods}

\subsection{Obtaining the Genomic Sequence}

The genomic sequence of the Rocio virus was obtained from the NCBI Viral Genomes Resource [21], under access code NC_040776.1 [22]. The coding regions were identified based on the most recent annotation of the genome and their virtual translation was used to obtain three-dimensional structures for all viral proteins.

\subsection{Protein Structure Prediction}

Possible template structures were identified based on the similarity of amino acid sequences by BLAST search [23] in the RCSB Protein Data Bank [24] with structural modeling of proteins being performed using the I-TASSER pipeline [25]. The C-Score and the TM-Score were analyzed to assess the confidence value, quality, and similarity of models. Moreover, the generated models were validated for permitted distribution of residues 
by Ramachandran plot. Additional model evaluation was performed using SwissModel tools [26].

\subsection{Potential Targets Selection and Drug Virtual Screening}

Proteins with the potential for high druggability, i.e., the potential to be inhibited to the point of weakening or hampering the viral cycle, were selected based on the literature available for taxonomically close viruses. The identity degree between viral and human proteins was considered for potential off-target effects. The identification of inhibitor candidates for the target proteins was performed by virtual screening $[27,28]$, using the ZINC database of molecular structures [29] and the molecular docking server DockThor [30]. The selected subset contained 1657 molecules. All molecules were approved by the Food and Drug Administration (FDA) and were additionally filtered for availability in the National List of Essential Medicines (RENAME) of the Brazilian Unified Health System (SUS), one of the widest public health care systems in the world [31]. These molecules were of particular interest to the authors due to their potential immediate application in case of infection re-emergence in the country. DockThor dedicated virtual screening tools were employed for the docking calculations. Each previously modeled structure was paired with the selected subset, using standard parameters for the primary blind virtual screening. For proteins with more than one domain, docking was performed for separate domains and complete structures.

Each protein's top 50 results were evaluated and explored according to their presence at RENAME. We subsequently analyzed the best score results according to their frequency and pharmacological characteristics. A refined docking was performed using proteins that demonstrated interaction with the sorted molecules, employing the following parameters: grid box edges measuring $8 \AA \times 18 \AA \times 15 \AA$ with a discretization of $0.25 \AA$, and a standard search algorithm. Resulting conformers were clustered at $2 \AA$ of RMSD. Drugtarget interactions were inspected via PLIP [32] and LigPlot+ [33]. All visualizations and molecular manipulations were performed with UCSF Chimera [34].

\subsection{Molecular Simulations}

Molecular simulations were based on the docked structures obtained from the docking calculations. The NS1 protein and NS1 in complex with the ITC molecule were chosen to perform MD simulation studies. The two systems were embedded in explicit water molecules, while $\mathrm{Cl}$ - and $\mathrm{Na}+$ ions were added to neutralize and reach the molar concentration of $0.15 \mathrm{M}$, leading to an orthorhombic periodic cell. The simulation cell for the systems were of $\sim 110 \times 130 \times 80 \AA$ containing a total of $\sim 130,000$ atoms.

All-atom molecular dynamics (MD) simulations were performed using the Amber ff19SB [35] force field, and GAFF [36] (general AMBER force field) parameters via Antechamber for the ITC molecule. The charge parameter of the ITC molecule was assigned using AM1-BCC atomic charge [37] and the OPC model [38] was used for water. An integration time step of $2 \mathrm{fs}$ was employed and all bond lengths involving hydrogen atoms were constrained. Temperature control was performed at $298 \mathrm{~K}$ via Langevin dynamics [39] with a collision frequency of $\gamma=1 / \mathrm{ps}$. Pressure control was accomplished by coupling the system to a Monte Carlo barostat [40] at a reference pressure of $1 \mathrm{~atm}$ and with a relaxation time of 2 ps. The systems were subjected to energy minimization to relax water molecules and counter ions, keeping the protein and ligand fixed with harmonic position restraints of $800 \mathrm{KJ} / \mathrm{mol}$. The systems were then equilibrated in the canonical ensemble (NVT) by running one 10-ns simulation while imposing position restraints of $800 \mathrm{KJ} / \mathrm{mol}$. Finally, 40-ns production runs were carried out for all the systems in an NPT ensemble in five replicates starting from different coordinates and velocities. These simulations were carried out using the GPU-accelerated version of OpenMM 7.6 [41] engine and the 'Making it rain' [42] cloud-based molecular simulations notebook environment. Overall, $40 \mathrm{~ns}$ of MD simulations were obtained for each replicate, providing $200 \mathrm{~ns}$ of ensembles for each system (NS1 and NS1 + ITC). The binding free energy for the association of ITC with NS1 was 
calculated using the Molecular Mechanics with Generalized Born and Surface Area (MMGBSA) method [43]. Using this method, we calculated the interaction energy and solvation free energy for the complex, receptor, and ligand and averaged the results to obtain an estimate of the binding free energy. Binding free energy calculations were performed over the 200 ns ensemble. The GBn model described by Mongan et al. was employed [43]. Pytraj [44] and ProLIF [45] packages were used for analysis of the MD ensembles.

\section{Results and Discussion}

\subsection{ROCV Structural and Nonstructural Protein Modeling}

As with other flaviviruses, ROCV genomic polyproteins are processed into mature proteins after specific enzymatic cleavages in the host cell's endoplasmic reticulum (ER) [46]. Based on the ROCV polyprotein amino acid sequence, which contains 3425 residues and 16 coding regions, we obtained 11 prototypes representing structural and nonstructural proteins of the virus. The individualized domains belonging to three of these proteins (protein E of the envelope, NS3, and NS5) were elucidated separately (Supplementary Box S1). The modeling results are described in Supplementary Table S1 and were used to perform the virtual screening.

The virus has three structural proteins: capsid protein $(C)$, envelope protein $(E)$, and membrane protein $(\mathrm{M})$, which were cleaved from the PrM propeptide after its translation (Figure 1A). These proteins have a binding function to the host cell, inducing the viral genome penetration into the cytoplasm after its partial fusion as well as assisting in the assembly, budding, and maturation of the new viral particles. Nonstructural proteins (NS1, NS2A/B, NS3, NS4A/B, and NS5) are present mainly in the ER and play the central role in viral replication (Figure 1B) [47].

By comparing amino acid sequences, we were able to identify similar proteins in the PDB database and evaluate their similarity with other flaviviruses (data not shown). This step proved to be essential since the ROCV protein structures are not resolved or incorporated in any database. Only three proteins had no matches in this search: nonstructural protein 2A (NS2A) and non-structural proteins 4A and 4B (NS4A/NS4B). This could justify lower quality models compared to those that have at least partial direct templates. 

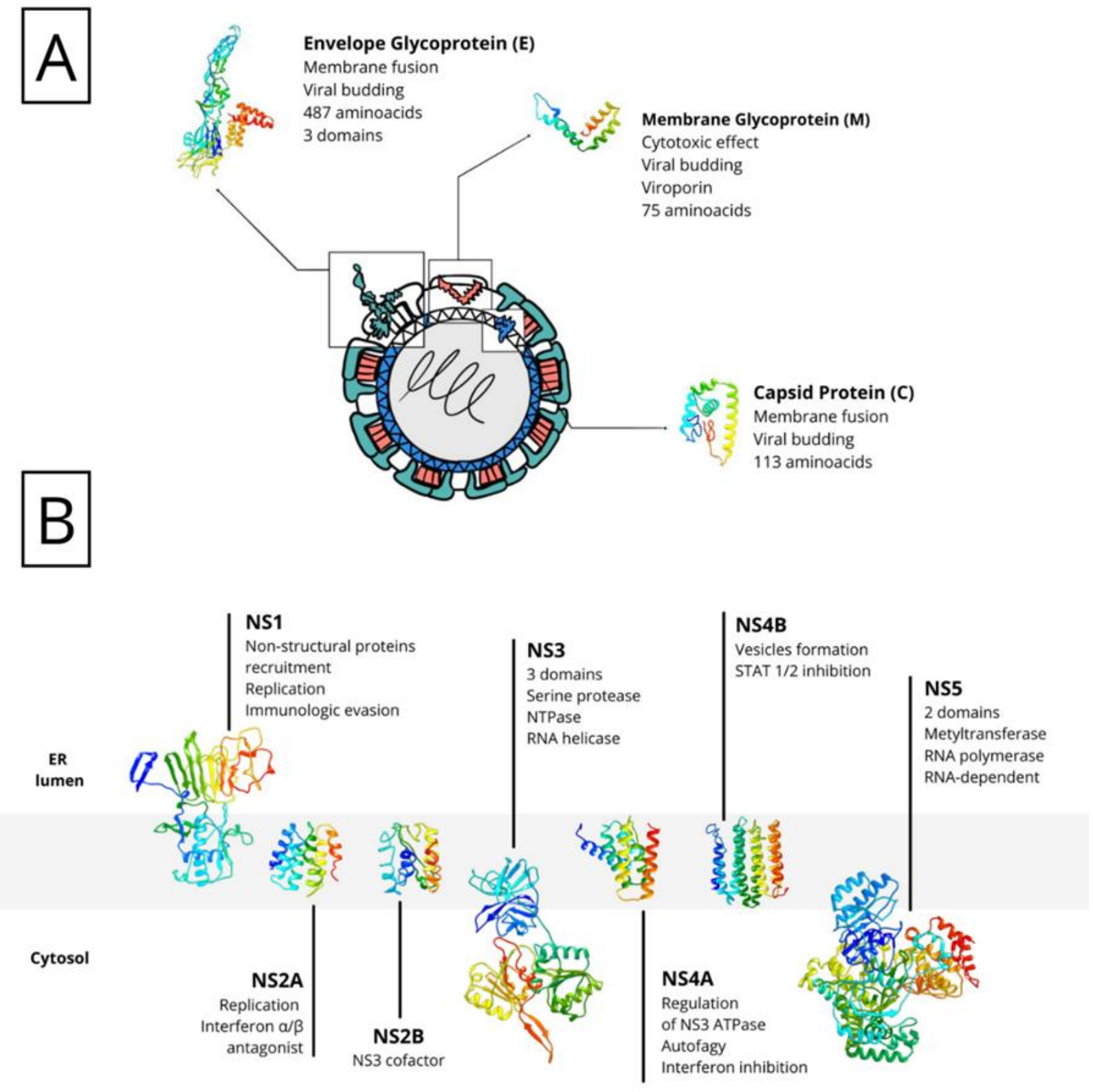

Figure 1. Schematic representation of ROCV proteins. The genome polyprotein is cleaved after translation into two types of proteins: structural proteins (A), present in the viral particle and responsible for viral assembly, evasion, and invasion; and non-structural proteins (B), present mainly in the endoplasmic reticulum (ER) and needed for the production of new virions.

\subsection{RENAME Drugs Have Potential to Become ROCV Treatment Precandidates}

The assessment of potential druggability of the selected targets was performed over a subset containing 1657 molecules and encompassing only FDA-approved drugs deposited in the DrugBank. This database was submitted to the DockThor platform along with the 19 previously modeled ROCV targets. During the blind virtual screening, 24 molecules considered structurally invalid by the platform were excluded, resulting in 1633 submitted molecules. At the end of the docking, the 50 molecules with the best scores for each of the targets were selected for further analysis, totaling 950 molecules.

RENAME is an improved and published list that guarantees access and pharmaceutical care within the scope of the SUS. It includes traditional medicines, specialized drugs, supplies, and vaccines. A manual filtering of 950 molecules was performed according to the 2020 version of RENAME to select available drugs. This selection included drugs present in 
this version, with or without combined use, and those excluded from this version. Of these 950 molecules, about $19.4 \%$ were present, $3 \%$ of which were excluded from the current version. It must be considered that the molecules present in the list may or may not repeat in the same or different dockings. Moreover, the atracurium/cisatracurium molecules, which are not present in the list, were found among the most prevalent and best-scored molecules (Supplementary Table S2).

The target with the highest scores and an interesting number of ligands available at RENAME was NS5. This protein has 813 amino acids and is located mainly in the nucleus of the host cell; however, it can be found in the membrane of the endoplasmic reticulum and budding vesicles. It can form homodimers and has post-translational modifications by phosphorylation of serine residues, which stimulates nuclear localization. In addition, it interacts with the NS3 protease [47].

Furthermore, NS5 is the most conserved protein in the flavivirus genome and has the function of replicating the viral genome and capping the genomes in the cytoplasm, methylating guanine N-7 and ribose $2^{\prime}-\mathrm{O}$. It also inhibits phosphorylation of STAT2 and TYK2, preventing JAK-STAT signaling and antiviral action of the cell. Two NS5 protein domains are known: a methyltransferase domain (MTase) in the N-terminal region and an RNA-dependent RNA polymerase domain in the C-terminal. It is also estimated that NS5 has interferon-blocking and cytokine-producing activities [48].

Considering the other molecular targets, we observed the highest scores on protein $\mathrm{E}$ of the envelope, followed by nonstructural proteins NS1, NS4B, and C. The most frequent molecules among the best scores were the antifungal agents itraconazole and ketoconazole (present in 15 of the 19 targets), the antivirals simeprevir and daclatasvir, and the antihypertensive iloprost. Also of note were the antiretrovirals saquinavir and lopinavir.

In order to select the best molecules and targets for repositioning, we sought to evaluate the best scores within the selected RENAME molecules, their frequency and absence at docking, and their dosage, toxicity, and use properties.

Four molecules were selected (simeprevir, daclatasvir, iloprost, and itraconazole) based on the following criteria: best score, different drug classes, route of administration, and possibility of use in specific groups (children, pregnant women, and the elderly). The molecules were screened based on the DrugBank database and the various factors considered were use, dosage, contraindications, and molecular aspects (Table 1). After this evaluation, only the itraconazole (ITC) and daclatasvir (DAC) were selected for further analysis of specific docking at the active protein site. The NS4A and glycoprotein M proteins were excluded from the analyses as they did not provide sufficient results.

Interestingly, Montes-Grajales et al. [49] performed an in silico identification of potential molecules for repositioning and use in the treatment of dengue, zika, and chikungunya. Five molecules, pranlukast, nilotinib, conivaptan, ITC, and novobiocin, were selected for in vitro analysis. Although itraconazole demonstrated good affinity in silico, it did not show significant antiviral activity in vitro.

Other authors have reported the antiviral activity of itraconazole; however, most of these activities are related to respiratory viruses, such as rhinovirus, influenza A, and more currently, the SARS-Cov-2 virus, highlighting that the antiviral activity of this antifungal agent should be investigated further for the treatment of the flaviviruses [50-57]. 
Table 1. Particular aspects of preselected molecules. Available on Pubchem (https:/ / pubchem.ncbi.nlm.nih.gov/) and DrugBank (https:/ / go.drugbank.com/) databases under the numbers 25154714, 5311181, 55283, 24,873,435 and DB09102, DB01088, DB01167, DB06290, respectively (accessed on 1 November 2021).

\begin{tabular}{|c|c|c|c|c|c|c|}
\hline Drug & $\begin{array}{l}\text { Molecular Weight } \\
\text { (Da) }\end{array}$ & Group & Administration & Indication & Target & Adverse Effects \\
\hline Daclatasvir & 738.89 & Antiviral & Oral & Hepatitis C & NS5A & $\begin{array}{l}\text { Headache, fatigue, nausea, } \\
\text { and diarrhea }\end{array}$ \\
\hline Iloprost & 360.49 & Antihypertensive & $\begin{array}{l}\text { Inhaled } \\
\text { Intravenous }\end{array}$ & $\begin{array}{l}\text { Pulmonary arterial } \\
\text { hypertension }\end{array}$ & Prostacyclin receptor & $\begin{array}{l}\text { Neuropathy, nausea, } \\
\text { headache, leukopenia, and } \\
\text { cardiac effects }\end{array}$ \\
\hline Itraconazole & 705.63 & Antifungal & $\begin{array}{c}\text { Oral } \\
\text { Intravenous }\end{array}$ & $\begin{array}{l}\text { Blastomycosis, histoplasmosis, } \\
\text { aspergillosis, and } \\
\text { onychomycosis }\end{array}$ & $\begin{array}{l}\text { Cytochrome P450 } \\
14 \alpha \text {-demethylase }\end{array}$ & $\begin{array}{c}\text { Thrombocytopenia, } \\
\text { bronchospasm, nasal } \\
\text { congestion, diarrhea, } \\
\text { tachycardia, and hypotension }\end{array}$ \\
\hline Simeprevir & 749.94 & Antiviral & Oral & Hepatitis C & NS3/4A & $\begin{array}{l}\text { Headache, fatigue, nausea, } \\
\text { and diarrhea }\end{array}$ \\
\hline
\end{tabular}




\subsection{ITC Interacts with Multiple ROCV Targets Including NS1}

After the selection of ITC and DAC, we carried out new directed dockings with the target proteins using more refined analysis parameters. The flowchart of the selection of candidate drugs is described in Figure 2.

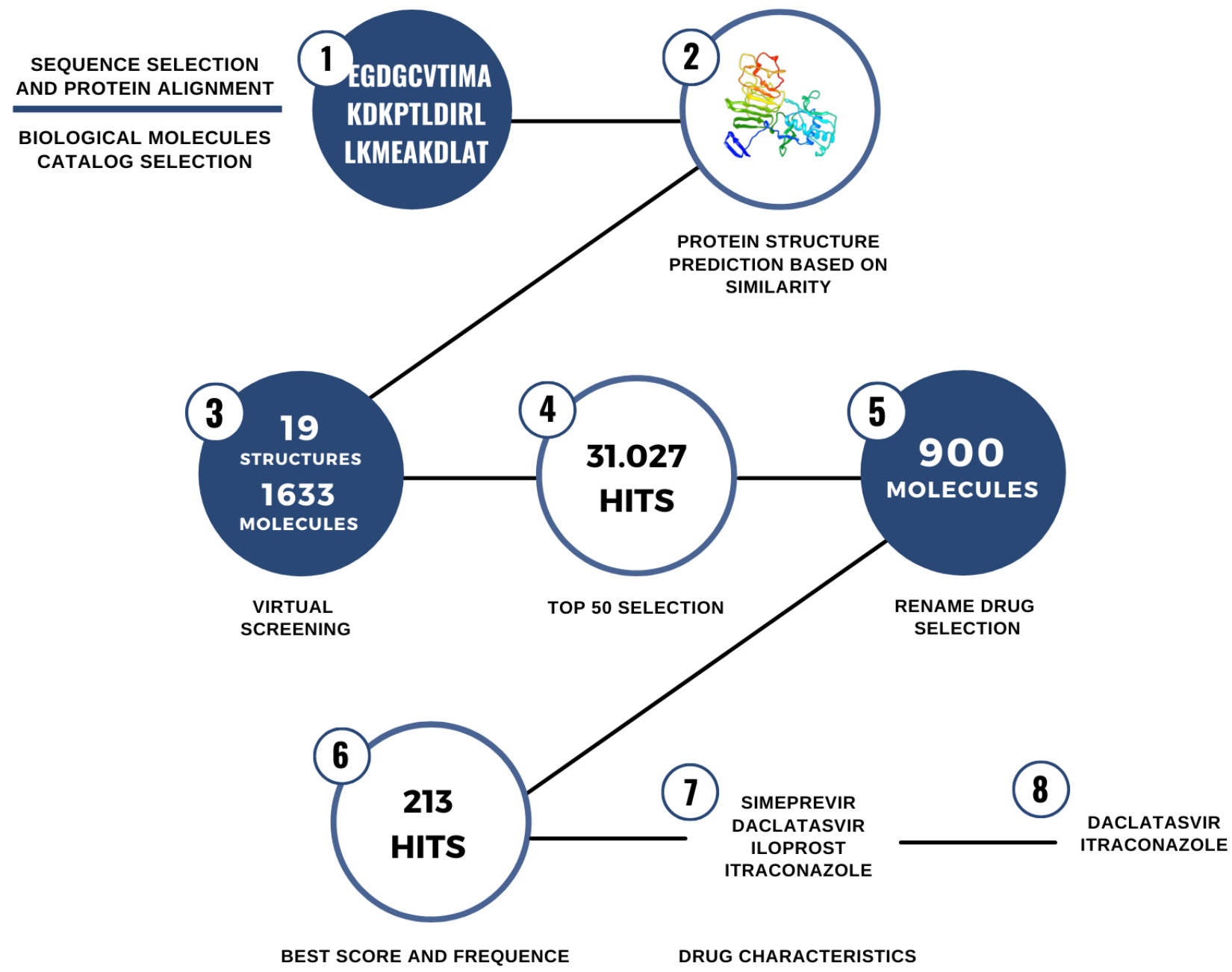

Figure 2. Steps for the identification of drug repurposing candidates for use against ROCV proteins.

DAC is an agent capable of preventing viral replication during hepatitis $\mathrm{C}$ virus (HCV) infection by binding to NS5 [50]. Since HCV is a flavivirus, we could expect a similar interaction between this drug and ROCV proteins. ITC is a large triazole antifungal that inhibits the ergosterol synthesis pathway and is indicated for treating fungal infections such as aspergillosis [51].

Our further analyses demonstrated an improvement in interactions between ITC and the proteins C, propeptide, E, NS1, NS2A, NS2B, NS3, NS4B, and N5A, as shown in Figure 3. However, this same improvement was not observed when applying the new parameters for DAC.

The NS1 protein was found to be an interesting target for this drug, since it was the best scored candidate. This 355 amino acid protein is located in the endoplasmic reticulum, is secreted N-glycosylated in homohexameric form, and interacts with the E protein and NS4B. It also interacts with the host CFH complement protein leading to C3 degradation. It has three destinations after its cleavage: (i) the replication cycle, where it is necessary for the formation of the replication complex and recruitment of other NS proteins in the ER membrane structures; (ii) the plasma membrane; and (iii) the extracellular compartment, 
where it is excreted in lipoparticles, antagonizes complement function, and aids in the evasion of the immune system [47]. We highlight the ITC-NS1 interaction in Figure 4.
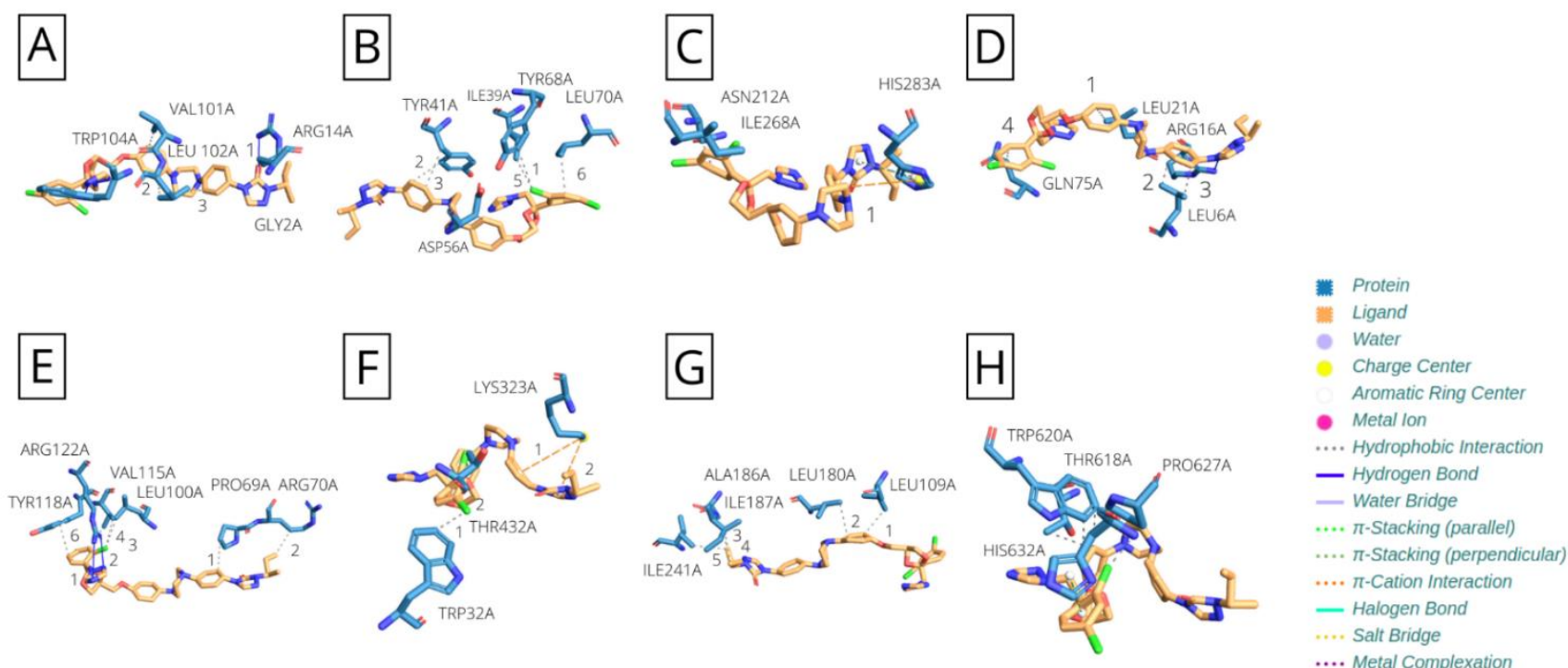

Figure 3. Itraconazole interaction with ROCV proteins. (A) Capsid protein; (B) polyprotein propeptide; (C) envelope glycoprotein; (D) NS2A; (E) NS2B; (F) NS3; (G) NS4B; and (H) NS5.

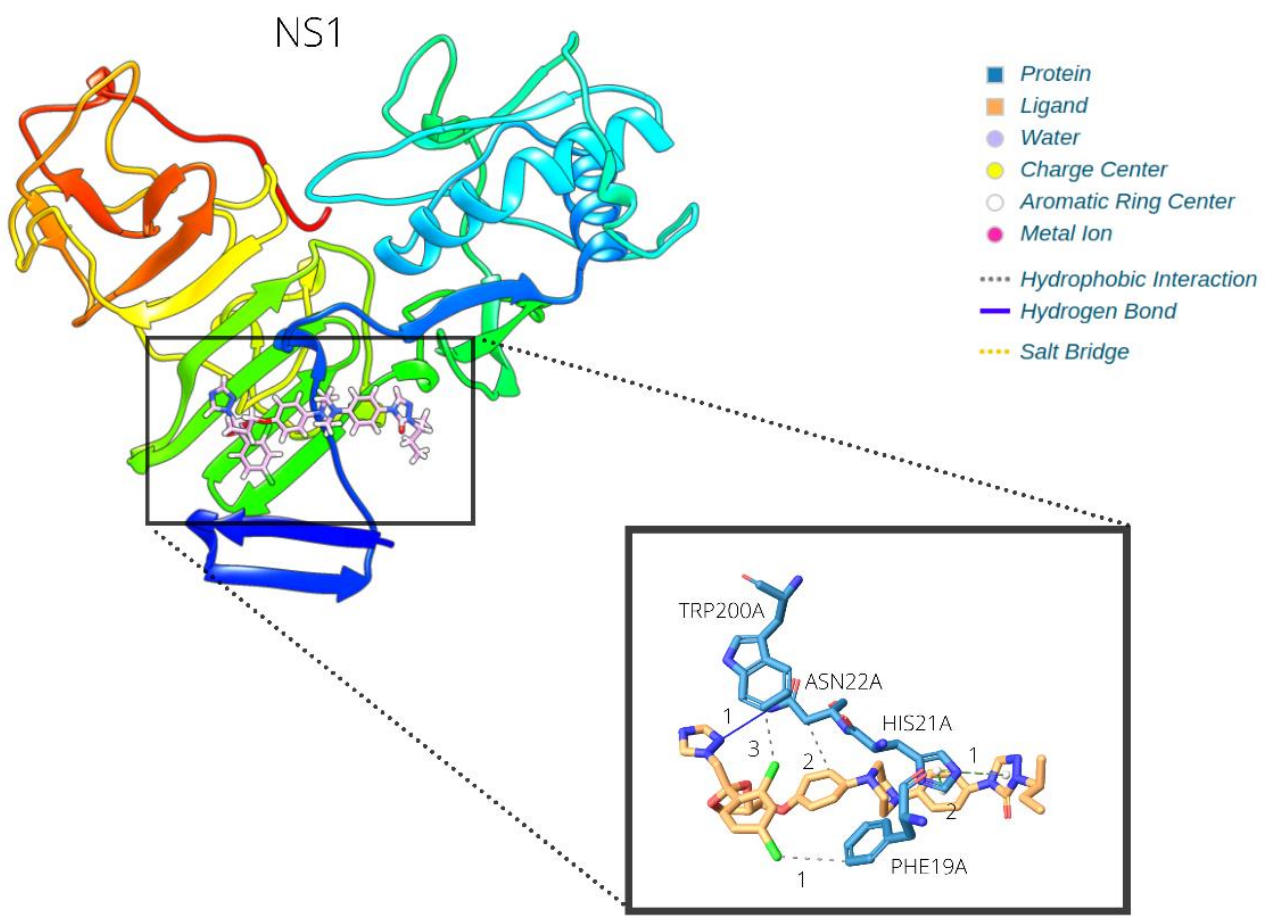

Figure 4. Itraconazole-NS1 interaction.

Molecular dynamics simulations of the NS1-itraconazole docked structure revealed great stability of the proposed complex (Figure 5A,B; Supplementary Figure S1C), mainly through van der Waals (Figure 5B) and hydrophobic interactions (Figure 5C). The ligandbinding free energy estimation (Table 2) has confirmed these favorable interactions. Additional residue-ligand interactions are established during simulation (Figure 5C), mainly hydrophobic and pi-pi stacking interactions, when compared to the original docking pose (Figure 4). All of these interactions seem to be important and favorable to keep the ligand 
bound to the protein. Such interactions seem to disturb protein packing contacts, rendering

NS1 locally more flexible when bound to ITC (Supplementary Figure S1A,B).
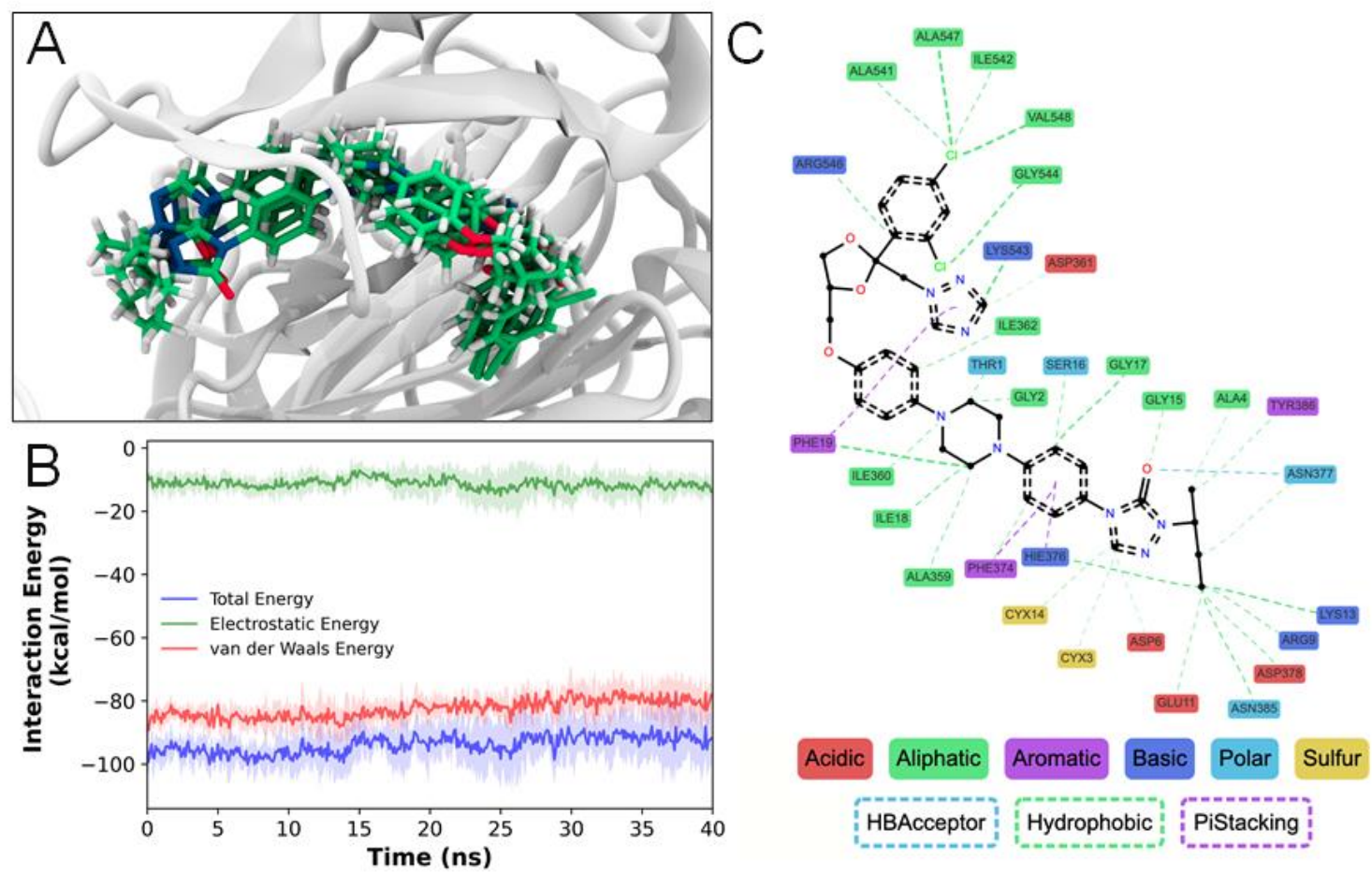

Figure 5. Simulation of itraconazole-NS1 interaction by molecular dynamics. (A) Final frames from simulation replicas highlighting the ITC position conservation throughout the simulations. (B) Stable, favorable interaction energies obtained from the simulations (dark colors-average; lighter colorsstandard deviation). (C) NSI-ITC interactions observed for at least 70\% of the simulation time.

Table 2. Estimated ligand-binding free energy.

\begin{tabular}{lc}
\hline & MM-GBSA (kcal/mol) \\
\hline Replica 1 & $-53.696 \pm 3.945$ \\
Replica 2 & $-51.634 \pm 6.155$ \\
Replica 3 & $-56.902 \pm 5.325$ \\
Replica 4 & $-55.809 \pm 5.933$ \\
Replica 5 & $-47.312 \pm 4.701$ \\
Average & $-53.071 \pm 3.399$ \\
\hline
\end{tabular}

Several authors have suggested the importance of the NS1 protein in different arboviral infections, which indicates that this could be an interesting target for therapeutics [52-54]. As previously reported [49], ITC has a virtual interaction with arboviral proteins. However, since it demonstrated no viral inhibition in vitro for ZIKV and DENV, its potential for treating rare emergent flavivirus remains unknown.

In our study, we investigated the interaction of the FDA-approved drugs available at the no-cost public health care system in Brazil with an emergent flavivirus. We suggested that itraconazole could be an exciting candidate for rapid drug repurposing in case of an emergency or re-emergency of ROCV infections in Brazil. This molecule demonstrated interactions with most of ROCV's proteins, which may point to an interesting multitarget drug. However, the binding profile with NS1, via hydrophobic and pi-pi stacking interactions, seemed to be most favored in this protein, pointing to its greater potential as a target candidate. 
Supplementary Materials: The following supporting information can be downloaded at: https: / / www.mdpi.com/article/10.3390/macromol2010006/s1, Box S1: ROCV proteins and their protein family (Pfam) catalogue entry; Table S1: Parameters from structural elucidation of ROCV proteins; Table S2: Docking results for selected drugs available at RENAME and ROCV proteins; Figure S1: NS1 and NSI-ITC molecular dynamics simulation analysis.

Author Contributions: J.P.S., P.R.A., C.P. and R.L.-B. contributed to the conceptualization, methodology, investigation, data curation, and writing during original draft preparation. J.P.S. and R.L.-B. performed review, editing, and writing of the final presentation. All authors have read and agreed to the published version of the manuscript.

Funding: This work received no direct funding (public or otherwise).

Institutional Review Board Statement: Not applicable.

Informed Consent Statement: Not applicable.

Data Availability Statement: All data presented here are available from the authors upon reasonable request.

Acknowledgments: The authors thank the DockThor team for the virtual screening server access granted for use in this work.

Conflicts of Interest: The authors declare no conflict of interest.

\section{References}

1. Duarte, J.L.; Diaz-Quijano, F.A.; Batista, A.C.; Giatti, L.L. Climatic variables associated with dengue incidence in a city of the Western Brazilian Amazon region. Rev. Soc. Bras. Med. Trop. 2019, 52, e20180429. [CrossRef] [PubMed]

2. Young, P.R. Arboviruses: A Family on the Move. In Dengue and Zika: Control and Antiviral Treatment Strategies. Advances in Experimental Medicine and Biology; Hilgenfeld, R., Vasudevan, S., Eds.; Springer: Singapore, 2018; Volume 1062, pp. 1-10. [CrossRef]

3. De Souza Lopes, O.; Coimbra, T.L.; de Abreu Sacchetta, L.; Calisher, C.H. Emergence of a new arbovirus disease in Brazil. I. Isolation and characterization of the etiologic agent, Rocio virus. Am. J. Epidemiol. 1978, 107, 444-449. [CrossRef] [PubMed]

4. De Souza Lopes, O.; de Abreu Sacchetta, L.; Coimbra, T.L.; Pinto, G.H.; Glasser, C.M. Emergence of a new arbovirus disease in Brazil. II. Epidemiologic studies on 1975 epidemic. Am. J. Epidemiol. 1978, 108, 394-401. [CrossRef] [PubMed]

5. Ellwanger, J.H.; Kaminski, V.L.; Chies, J.A.B. Rocio virus: An overview. Rev. Peru. Divulg. Cient. Genét. Biol. Mol. 2017, 1, 14-20.

6. Saivish, M.V.; Gomes da Costa, V.; de Lima Menezes, G.; Alves da Silva, R.; Dutra da Silva, G.C.; Moreli, M.L.; Sacchetto, L.; Pacca, C.C.; Vasilakis, N.; Nogueira, M.L. Rocio Virus: An Updated View on an Elusive Flavivirus. Viruses 2021, 13, 2293. [CrossRef] [PubMed]

7. Figueiredo, L.T. The Brazilian flaviviruses. Microbes Infect. 2000, 2, 1643-1649. [CrossRef]

8. Iversson, L.B. Aspects of the encephalitis epidemic caused by arbovirus in the Ribeira Valley, S. Paulo, Brazil, during 1975-1978. Rev. Saúde Pública 1980, 14, 9-35. [CrossRef]

9. Romano-Lieber, N.S.; Iversson, L.B. Serological survey on arbovirus infection in residents of ecological reserve. Rev. Saúde Pública 2000, 34, 236-242. [CrossRef]

10. Medeiros, D.B.A.; Nunes, M.R.T.; Vasconcelos, P.F.C.; Chang, G.J.; Kuno, G. Complete genome characterization of Rocio virus (Flavivirus: Flaviviridae), a Brazilian flavivirus isolated from a fatal case of encephalitis during an epidemic in Sao Paulo state. J. Gen. Virol. 2007, 88, 2237-2246. [CrossRef]

11. de Souza Lopes, O.; de Abreu Sacchetta, L.; Francy, D.B.; Jakob, W.L.; Calisher, C.H. Emergence of a new arbovirus disease in Brazil. III. Isolation of Rocio virus from Psorophora Ferox (Humboldt, 1819). Am. J. Epidemiol. 1981, 113, 122-125. [CrossRef]

12. Mitchell, J.C.; Forattini, O.P.; Miller, B.R. Vector competence experiments with Rocio virus and three mosquito species from the epidemic zone in Brazil. Rev. Saúde Pública 1986, 20, 171-177. [CrossRef] [PubMed]

13. Saivish, M.V.; da Costa, V.G.; Rodrigues, R.L.; Féres, V.C.R.; Montoya-Diaz, E.; Moreli, M.L. Detection of Rocio Virus SPH 34675 during Dengue Epidemics, Brazil, 2011-2013. Emerg. Infect. Dis. 2020, 26, 797-799. [CrossRef]

14. Tavares-Neto, J.; Travassos da Rosa, A.P.A.; Vasconcelos, P.F.C.; Costa, J.M.L.; Travassos da Rosa, J.F.S.; Marsden, P.D. Research of antibodies to arbovirus in the serum of residents of the village of Corte de Pedra, Valença, Bahia. Mem. Inst. Oswaldo. Cruz 1986, 81, 351-358. [CrossRef] [PubMed]

15. Straatmann, A.; Santos-Torres, S.; Vasconcelos, P.F.C.; Travassos da Rosa, A.P.A.; Rodrigues, S.G.; Tavares-Neto, J. Serological evidence of the circulation of the Rocio arbovirus (Flaviviridae) in Bahia. Rev. Soc. Bras. Med. Trop. 1997, 30, 511-515. [CrossRef] [PubMed]

16. Casseb, A.R.; Cruz, A.V.; Jesus, I.S.; Chiang, J.O.; Martins, L.C.; Silva, S.P.; Henriques, D.F.; Casseb, L.M.N.; Vasconcelos, P.F.C. Seroprevalence of flaviviruses antibodies in water buffaloes (Bubalus bubalis) in Brazilian Amazon. J. Venom. Anim. Toxins Trop. Dis. 2014, 20, 9. [CrossRef] 
17. Lopes, N.; Linhares, R.E.C.; Nozawa, C. General features and epidemiology of emerging arboviruses in Brazil. Rev. Pan-Amaz. Saude 2014, 3, 55-64. [CrossRef]

18. Farha, M.A.; Brown, E.D. Drug repurposing for antimicrobial discovery. Nat. Microbiol. 2019, 4, 565-577. [CrossRef]

19. Petrova, E. Innovation in the pharmaceutical industry: The process of drug discovery and development. In Innovation and Marketing in the Pharmaceutical Industry Emerging Practices, Research, and Policies; Ding, M., Eliashberg, J., Stremersch, S., Eds.; Springer: New York, NY, USA, 2018; pp. 19-81. [CrossRef]

20. Zheng, W.; Sun, W.; Simeonov, A. Drug repurposing screens and synergistic drug-combinations for infectious diseases. Br. J. Pharmacol. 2017, 175, 181-191. [CrossRef]

21. NCBI Resource Coordinators. Database resources of the National Center for Biotechnology Information. Nucleic Acids Res. 2018, 46, D8-D13. [CrossRef]

22. Kuno, G.; Chang, G.J.; Tsuchiya, K.R.; Karabatsos, N.; Cropp, C.B. Phylogeny of the genus Flavivirus. J. Virol. 1998, 72, 73-83. [CrossRef]

23. Altschul, S.F.; Gish, W.; Miller, W.; Myers, E.W.; Lipman, D.J. Basic local alignment search tool. J. Mol. Biol. 1990, 215, 403-410. [CrossRef]

24. Berman, H.M.; Westbrook, J.; Feng, Z.; Gilliland, G.; Bhat, T.N.; Weissig, H.; Shindyalov, I.N.; Bourne, P.E. The Protein Data Bank. Nucleic Acids Res. 2000, 28, 235-242. [CrossRef] [PubMed]

25. Yang, J.; Yan, R.; Roy, A.; Xu, D.; Poisson, J.; Zhang, Y. The I-TASSER Suite: Protein structure and function prediction. Nat. Methods 2015, 12, 7-8. [CrossRef] [PubMed]

26. Arnold, K.; Bordoli, L.; Kopp, J.; Schwede, T. The SWISS-MODEL workspace: A web-based environment for protein structure homology modelling. Bioinformatics 2006, 22, 195-201. [CrossRef]

27. Schneider, G. Virtual screening: An endless staircase? Nat. Rev. Drug Discov. 2010, 9, 273-276. [CrossRef]

28. Sliwoski, G.; Kothiwale, S.; Meiler, J.; Lowe, E.W., Jr. Computational methods in drug discovery. Pharmacol. Rev. 2014, 66, 334-395. [CrossRef]

29. Sterling, T.; Irwin, J.J. ZINC 15Ligand Discovery for Everyone. J. Chem. Inf. Model. 2015, 55, 2324-2337. [CrossRef]

30. De Magalhães, C.S.; Almeida, D.M.; Barbosa, H.J.C.; Dardenne, L.E. A dynamic niching genetic algorithm strategy for docking highly flexible ligands. Inf. Sci. 2014, 289, 206-224. [CrossRef]

31. Brasil. Ministério da Saúde. Secretaria de Ciência, Tecnologia, Inovação e Insumos Estratégicos em Saúde. Departamento de Assistência Farmacêutica e Insumos Estratégicos. Relação Nacional de Medicamentos Essenciais: Rename 2020 [Recurso Eletrônico]/Ministério da Saúde, Secretaria de Ciência, Tecnologia, Inovação e Insumos Estratégicos em Saúde, Departamento de Assistência Farmacêutica e Insumos Estratégicos-Brasília: Ministério da Saúde. 2020; p. 217. Available online: https: //bvsms.saude.gov.br/bvs/publicacoes/relacao_medicamentos_rename_2020.pdf (accessed on 25 January 2021).

32. Salentin, S.; Schreiber, S.; Haupt, V.J.; Adasme, M.F.; Schroeder, M. PLIP: Fully automated protein-ligand interaction profiler. Nucleic Acids Res. 2015, 43, W443-W447. [CrossRef]

33. Laskowski, R.A.; Swindells, M.B. LigPlot+: Multiple ligand-protein interaction diagrams for drug discovery. J. Chem. Inf. Model. 2011, 51, 2778-2786. [CrossRef]

34. Pettersen, E.F.; Goddard, T.D.; Huang, C.C.; Couch, G.S.; Greenblatt, D.M.; Meng, E.C.; Ferrin, T.E. UCSF Chimera-A visualization system for exploratory research and analysis. J. Comput. Chem. 2004, 25, 1605-1612. [CrossRef]

35. Tian, C.; Kasavajhala, K.; Belfon, K.; Raguette, L.; Huang, H.; Migues, A.N.; Bickel, J.; Wang, Y.; Pincay, J.; Wu, Q.; et al. ff19SB: Amino-Acid-Specific Protein Backbone Parameters Trained against Quantum Mechanics Energy Surfaces in Solution. J. Chem. Theory Comput. 2020, 16, 528-552. [CrossRef] [PubMed]

36. Wang, J.; Wolf, R.M.; Caldwell, J.W.; Kollman, P.A.; Case, D.A. Development and testing of a general amber force field. J. Comput. Chem. 2004, 25, 1157-1174. [CrossRef] [PubMed]

37. Jakalian, A.; Jack, D.B.; Bayly, C.I. Fast, efficient generation of high-quality atomic charges. AM1-BCC model: II. Parameterization and validation. J. Comput. Chem. 2002, 23, 1623-1641. [CrossRef] [PubMed]

38. Izadi, S.; Anandakrishnan, R.; Onufriev, A.V. Building Water Models: A Different Approach. J. Phys. Chem. Lett. 2014, 5, 3863-3871. [CrossRef]

39. Turq, P.; Lantelme, F.; Friedman, H.L. Brownian Dynamics: Its Applications to Ionic Solutions. J. Chem. Phys. 1977, 66, 3039. [CrossRef]

40. Åqvist, J.; Wennerström, P.; Nervall, M.; Bjelic, S.; Brandsdal, B.O. Molecular dynamics simulations of water and biomolecules with a Monte Carlo constant pressure algorithm. Chem. Phys. Lett. 2004, 384, 288-294. [CrossRef]

41. Eastman, P.; Swails, J.; Chodera, J.D.; McGibbon, R.T.; Zhao, Y.; Beauchamp, K.A.; Wang, L.-P.; Simmonett, A.C.; Harrigan, M.P.; Stern, C.D.; et al. OpenMM 7: Rapid development of high performance algorithms for molecular dynamics. PLoS Comp. Biol. 2017, 13, e1005659. [CrossRef]

42. Arantes, P.R.; Polêto, M.D.; Pedebos, C.; Ligabue-Braun, R. Making it Rain: Cloud-Based Molecular Simulations for Everyone. J. Chem. Inf. Model. 2021, 61, 4852-4856. [CrossRef]

43. Mongan, J.; Simmerling, C.; McCammon, J.A.; Case, D.A.; Onufriev, A. Generalized Born model with a simple, robust molecular volume correction. J. Chem. Theory Comput. 2007, 3, 156-169. [CrossRef]

44. Roe, D.R.; Cheatham, T.E., 3rd. PTRAJ and CPPTRAJ: Software for Processing and Analysis of Molecular Dynamics Trajectory Data. J. Chem. Theory Comput. 2013, 9, 3084-3095. [CrossRef] [PubMed] 
45. Bouysset, C.; Fiorucci, S. ProLIF: A library to encode molecular interactions as fingerprints. J. Cheminform. 2021, 13, 72. [CrossRef] [PubMed]

46. Hulo, C.; de Castro, C.E.; Masson, P.; Bougueleret, L.; Bairoch, A.; Xenarios, I.; Le Mercier, P. ViralZone: A knowledge resource to understand virus diversity. Nucleic Acids Res. 2011, 39, D576-D582. [CrossRef] [PubMed]

47. UniProt Consortium. UniProt: A worldwide hub of protein knowledge. Nucleic Acids Res. 2019, 47, D506-D515. [CrossRef]

48. Da Fonseca, N.J., Jr.; Lima Afonso, M.Q.; Pedersolli, N.G.; de Oliveira, L.C.; Andrade, D.S.; Bleicher, L. Sequence, structure and function relationships in flaviviruses as assessed by evolutive aspects of its conserved non-structural protein domains. Biochem. Biophys. Res. Commun. 2017, 492, 565-571. [CrossRef]

49. Montes-Grajales, D.; Puerta-Guardo, H.; Espinosa, D.A.; Harris, E.; Caicedo-Torres, W.; Olivero-Verbel, J.; Martínez-Romero, E. In silico drug repurposing for the identification of potential candidate molecules against arboviruses infection. Antiviral Res. 2020, 173, 104668. [CrossRef]

50. Smith, M.A.; Regal, R.E.; Mohammad, R.A. Daclatasvir: A NS5A Replication Complex Inhibitor for Hepatitis C Infection. Ann. Pharmacother. 2016, 50, 39-46. [CrossRef]

51. De Beule, K.; Van Gestel, J. Pharmacology of itraconazole. Drugs 2001, 61, 27-37. [CrossRef]

52. Chen, H.R.; Lai, Y.C.; Yeh, T.M. Dengue virus non-structural protein 1: A pathogenic factor, therapeutic target, and vaccine candidate. J. Biomed. Sci. 2018, 25, 58. [CrossRef]

53. Patel, S.; Sinigaglia, A.; Barzon, L.; Fassan, M.; Sparber, F.; LeibundGut-Landmann, S.; Ackermann, M. Role of NS1 and TLR3 in Pathogenesis and Immunity of WNV. Viruses 2019, 11, 603. [CrossRef]

54. Rastogi, M.; Sharma, N.; Singh, S.K. Flavivirus NS1: A multifaceted enigmatic viral protein. Virol. J. 2016, 13, 131. [CrossRef] [PubMed]

55. Schloer, S.; Goretzko, J.; Pleschka, S.; Ludwig, S.; Rescher, U. Combinatory Treatment with Oseltamivir and Itraconazole Targeting Both Virus and Host Factors in Influenza A Virus Infection. Viruses 2020, 12, 703. [CrossRef] [PubMed]

56. Shim, A.; Song, J.-H.; Kwon, B.-E.; Lee, J.-J.; Ahn, J.-H.; Kim, Y.-J.; Rhee, K.-J.; Chang, S.-Y.; Cha, Y.; Lee, Y.-S.; et al. Therapeutic and prophylactic activity of itraconazole against human rhinovirus infection in a murine model. Sci. Rep. 2016, 2016, 23110. [CrossRef] [PubMed]

57. Van Damme, E.; De Meyer, S.; Bojkova, D.; Ciesek, S.; Cinatl, J.; De Jonghe, S.; Jochmans, D.; Leyssen, P.; Buyck, C.; Neyts, J.; et al. In vitro activity of itraconazole against SARS-CoV-2. J. Med. Virol. 2021, 93, 4454-4460. [CrossRef] [PubMed] 